\title{
Positive and Negative Emotions and Nonattachment in Vietnamese Buddhists
}

\author{
Hang T. M. Nguyen ${ }^{1} \&$ Hoang V. Nguyen ${ }^{2}$ \\ ${ }^{1}$ Department of Psychology, University of Social Sciences and Humanities, Vietnam National University Hanoi, \\ Hanoi, Vietnam \\ ${ }^{2}$ Department of Psychology, University of Minnesota-Twin Cities, Minneapolis, MN, USA \\ Correspondence: Hang T. M. Nguyen, University of Social Sciences and Humanities, Vietnam National \\ University Hanoi, 336 Nguyen Trai, Thanh Xuan Trung, Thanh Xuan, Hanoi, Vietnam.
}

Received: December 28, 2017

Accepted: February 24, $2018 \quad$ Online Published: March 2, 2018

doi:10.20849/ajsss.v3i1.324

URL: https://doi.org/10.20849/ajsss.v3i1.324

\begin{abstract}
Several research have shown that nonattachment, a Buddhist practice, could reduce negative emotions and improve positive emotions (Sahdra \& Shaver, 2013; Sahdra, Shaver, \& Brown, 2010; Wang, Wong, \& Yeh, 2016; Wendling, 2012). We aimed to explore such influences in a sample of Vietnamese Buddhists $(N=472)$. Our methods included the State Trait Anxiety Inventory (STAI; Spielberger et al., 1983), the Nonattachment Scale (NAS; Sahdra et al., 2010), and a demographic and religious questionnaire. Results showed that positive emotion scores $(M=2.89, S D=.502)$ of participants were significantly higher than that of their negative emotion scores $(M=2.10, S D=.587, p<.001)$. People with strong religious commitment such as monks, lay-people who practiced at pagoda, and lay-people who practiced with sangha had higher positive emotion scores and less negative emotion scores than those whose religious commitment were weak. Nonattachment was positively correlated with positive emotions $(r=.47, p<.01)$ and negatively correlated with negative emotions $(r=-.37, p$ $<.01)$. Nonattachment could also explain $21.7 \%$ positive emotions variance $(p<.001)$ and $12.4 \%$ negative emotions variance $(p<.001)$. Nonattachment and religious commitment could, therefore, influence greatly positive emotions in Buddhists. This result suggested a discussion about applying nonattachment to prevent emotional problems and improve psychological well-being.
\end{abstract}

Keywords: positive and negative emotions, nonattachment, Buddhist psychology, psychology of religion

\section{Background}

Religion has always been an influential factor that affects how people may experience and perceive their emotions (Emmons \& Paloutzian, 2003). Many studies have found evidence supporting the link between various emotions or emotion-related variables and religiosity. These variables include love, sadness, shame, hope, optimism, altruism, and gratitude (Fiori, Brown, Cortina \& Antonucci, 2006; Kim-Prieto \& Diener, 2009; Koenig \& Larson, 2001; McCullough \& Willoughby, 2009; Myers, 1992; Pargament, Magyar- Russell, \& Murray-Swank, 2005; Park, 2005; Szekely, Opre, \& Miu, 2015). According to Emmons (2005), there are at least three plausible mechanisms through which religion dictates the experience of emotions. First, religion prescribes the desirability of different emotions, thus encouraging the adherents to actively seek and experience certain emotions while avoid others. For example, a study by Kim-Prieto and Diener (2009) that aimed to investigate the differences and similarities in the desired emotions across religions found that the belief about the desirability of emotions by the adherents influenced their experience of emotions.

Second, religion recommends the level of intensity with which emotions should be experienced, therefore monitoring the intensity of experienced emotions. A study by Tsai, Miao, and Seppala (2007) reported that several religions differed in the level of intensity that they valued and encouraged their practitioners to feel. For example, while both Christians and Buddhists wanted to experience more positive than negative feelings, Christians valued high arousal positive (HAP) states (e.g., excitement) more and low arousal positive (LAP) states (e.g., calm) less than Buddhists. Last, religions offer a number of practices that help religious followers experience the desired emotions at the preferred level. For instance, mindful breathing is commonly practiced in Buddhism and is said to have enormous effects on practitioners' emotions. Indeed, a study by Philippot, Chapelle, 
and Blairy (2002) showed that voluntarily changing the pattern of breath could account for at least $40 \%$ of the variance in feelings of anger, fear, joy, and sadness.

Another less well-known Buddhist practice that has been studied in psychology within a recent decade is nonattachment. Although there is relatively limited research on nonattachment, scholars have gained considerable insights on this subject. Several studies showed that nonattachment was positively correlated to satisfaction with life, subjective and eudemonic well-being, peace of mind, and pleasant affects (Sahdra et al., 2010; Wang, Wong \& Yeh, 2016). Furthermore, nonattachment was strongly correlated to cognitive empathy, affective empathy, and prosocial behavior (Sahdra, Ciarrochi, Parker, Marshall, \& Heaven, 2015). On the other hands, it has been shown that nonattachment is negatively correlated to unpleasant affects, difficulty in emotional regulation, including stress, anxiety, and depression, and low close-mindedness (Sahdra \& Shaver, 2013; Sahdra et al., 2010; Wang, Wong \& Yeh, 2016). Nonattachment was also a mediator between emotions and distress and could predict from eight to ten percent of emotional regulation (Coffey \& Hartman, 2008).

Aforementioned results suggested strong relationships between nonattachment and psychological well-being well-being and emotions. Additionally, those studies were conducted on diverse samples that consisted of both religious and non-religious individuals. Therefore, we asked if we could find any difference in the relationship between nonattachment and emotions using a sample of Buddhists, who practiced nonattachment frequently. Moreover, given that there is a disparity between Buddhist concepts of emotions and that of western psychology, how could we explain such a difference in terms of practicing nonattachment? These questions led us to scrutinize relationships between nonattachment and emotions, including positive and negative ones.

\section{Purpose of the Study}

We aimed to study relationships between nonattachment and positive and negative emotions.

\section{Research Questions}

Q1. Are there differences in the positive and negative emotions given demographical variables?

Q2. Are there differences in the positive and negative emotions given religious variables?

Q3. What is the relationship between positive and negative emotions and nonattachment?

\section{Definitions of Terms}

Nonattachment (viraga) is a Buddhist practice method. In terms of meaning, nonattachment conveys an absense of desire, lust, and greed. Yet, nonattachment does not imply a retreat from reality, but rather to balance one's emotions in such a way that he or she can truly observe the nature of things and phenomena. Nonattachment presents whenever a person perceives that no possession, relationship, or achievement can last permanently (Harris, 1997). The person, therefore, is no longer dependent on ideas, appereance, sensual experiences, and desires of possession and thus avoids enlarging his or her ego (Sahdra et al, 2010). The person will then realize that there is no self to protect and that searching for sensual satisfiction is to imprison oneself in obsession and sufferings. Some scholars have made effort to compare the Buddhist concept of nonattachment with western psychological attachment, secure attachment, and anxious attachment (Gleg, 2016; Sahdra, Shaver \& Brown, 2010). While secure attachment implies that happiness could be achieved by improving relationships with other people, nonattachment suggests that happiness is possible via working with our minds using mindfulness and meditation (Sahdra \& Shaver, 2013).

In Buddhism, nonattachment is one of the Four Immesurables that emphasizes letting go of unwholesome desires and discrimination in order to attain tranquility, equanimity, and steadiness, which are LAP. This will allow us to react properly when facing adversity and criticism, as well as serendipity and adulatory. Buddhist teaching discusses two levels of nonattachment, including nonattachment of materials such as items, money, and property, and nonattachment of immaterials that could prevent people from observing clearly the nature of reality such as unwholesome habits, biases, and greed.

In sum, nonattachment is a Buddhist practice that aims to balance one's emotions, thus allowing the practitioner to realize a deeper meaning of life accordingly to the Buddhist teachings. In regards to the Emmons' mechanisms, nonattachment prescribes the preferred level of intensity, as it values LAP more than HAP, and methods to experience valued emotions at the preferred level.

Emotions are psychological phenomena that reflects human attitude toward things, phenomena, other people, and themselves. This implies that when subjects (those who perceive) hold positive emotions, they are satisfied with themselves and the outside world; in contrast, when subjects hold negative emotions, they are not satisfied. The presence of positive emotions and the absence or reduction of negative ones are manifestation of a healthy 
mind. In Buddhism, a healthy mind includes joy and happiness, which convey gentleness and peace that emphasize low arousal positive emotions, as oppose to high arousal positive emotions (Silberman, 2005). Buddhist concepts of healthy emotions included non-agitation, balance, peace, and happiness and equanimity (Desbordes et al., 2015; Silva, 2013).

Therefore, a Buddhist healthy mind goes hand in hand with balancing emotions. Buddhists engage in practices that help them balance their emotions, so that when facing stressful factors, they will neither get lost in negative emotions such as painful, jealous, and hateful, nor be restrained by positive emotions such as passionate, excited, and jubilant. Buddhism emphasizes peacefulness and silence as they are said to be conditions that nurture and bring about insights. Such insights allow people to understand the nature of things and phenomena and thus to avoid reacting improperly and creating unwholesome consequences.

\section{Research Methods}

\subsection{Participants and Procedure}

This study was conducted in 2016. All participants had to meet the following criteria: a) being Buddhists, including monks, nuns, and laypeople who frequently practiced under guidance of monks and nuns or Buddhist teachings; b) participating in Buddhist lectures of Buddhist monks, directly or indirectly (e.g. via the Internet); c) frequently going to pagodas and taking part in Buddhist ceremonies; and d) having understandings of Buddhist teaching. Participants answered our survey at pagoda under guidance of researchers.

Our research was conducted on a pilot sample of 30 people and a study sample of 472 people. All 472 participants practiced in four Buddhist communities, or sanghas, but came from different provinces in the north of Vietnam. Each sangha did not follow a single tradition, but rather included distinguished traditions such as Zen Buddhism, Pure Land Buddhism, and Tantric Buddhism. Although our participants came from four different sanghas, the extent to which they practiced at these sanghas varied. While some people practiced at these sanghas frequently, others might practice elsewhere.

\subsection{Measures}

i) Positive and negative emotions. The State-Trait Anxiety Inventory (STAI; Spielberger, Gorsuch, Lushene, Vagg, \& Jacobs, 1983) includes positive and negative subscales (nine and 11 items, respectively). STAI was suitable for measuring Buddhists' emotions, because it included statements that describing emotions such as pleasant, relaxing, comfortable, happy, satisfactory, secured, and calm. STAI is a Likert-type scale that ranges from "Almost never" to "Almost always". The Cronbach's alpha of the two STAI subscales on the pilot sample were .84 and .79 and that on the study sample were .81 and .88 , respectively.

ii) Nonattachment. The Nonattachment Scale (NAS; Sahdra et al., 2010) is a Likert-type scale that includes 30 items with ratings that range from one ('disagree completely') to six ('agree completely'); high scores indicate a greater level of non-attachment. We adapted the scale on the pilot sample (Cronbach's alpha $=.86$ ) and the study sample (Cronbach's alpha $=.93$ ). The scale was indepdently translated by two translators and reviewed by a Buddhist researcher and two Buddhist monks.

\section{Results}

\subsection{Demographic and Religious Characteristics of Participants}

Participants included 130 men (27.7\%), 339 women (72.3\%) and three individuals who did not specify their gender. Participants ranged in age from 12 to 71 years, with a mean of 33.7 years $(S D=13.2)$. Approximately, half of the participants were not married (28.9\% without boyfriend/girlfriend and $15.8 \%$ with boyfriend/girlfriend), $37.1 \%$ were married, $8.3 \%$ were divorced, and $9.9 \%$ were monks and nuns. Participants had different occupational backgrounds and ranged in income from one to 25 million VND/month (one million VND $=46$ USD).

There were 45 monks and 427 laypeople, of whom 58.5\% had not taken refuge in the Three Jewels and $41.5 \%$ had, for a period of 1 to 22 years. Participants practiced Buddhism at pagodas (44.1\%), home (43.7\%), and other places $(12.2 \%)$. The number of participants who practiced alone, with family members, with friends, or with sangha were nearly equal. Among participants, 5.4\% hardly practiced Buddhism, whereas others practiced from several times a year $(21.8 \%)$ to everyday $(36.4 \%)$. The majority of participants had a solid belief in Buddhism (83.6\%) and assessed themselves as having changed positively since practicing Buddhism (93\%).

Results showed that a Buddhist mean score of positive emotions was $2.89(S D=.50)$ and that of negative emotions was $2.10(S D=.58)$. A paired samples $t$-test revealed that Buddhist positive emotion scores were significantly higher than Buddhist negative emotion scores, $t(471)=18.96, p<.001$. 


\subsection{Effects of Demographic Variables on Positive and Negative Emotions}

Effects of demographic variables on positive and negative emotions in Buddhists are described in Table 1.

Table 1. Relationships between emotion and demographic variables $(N=472)$

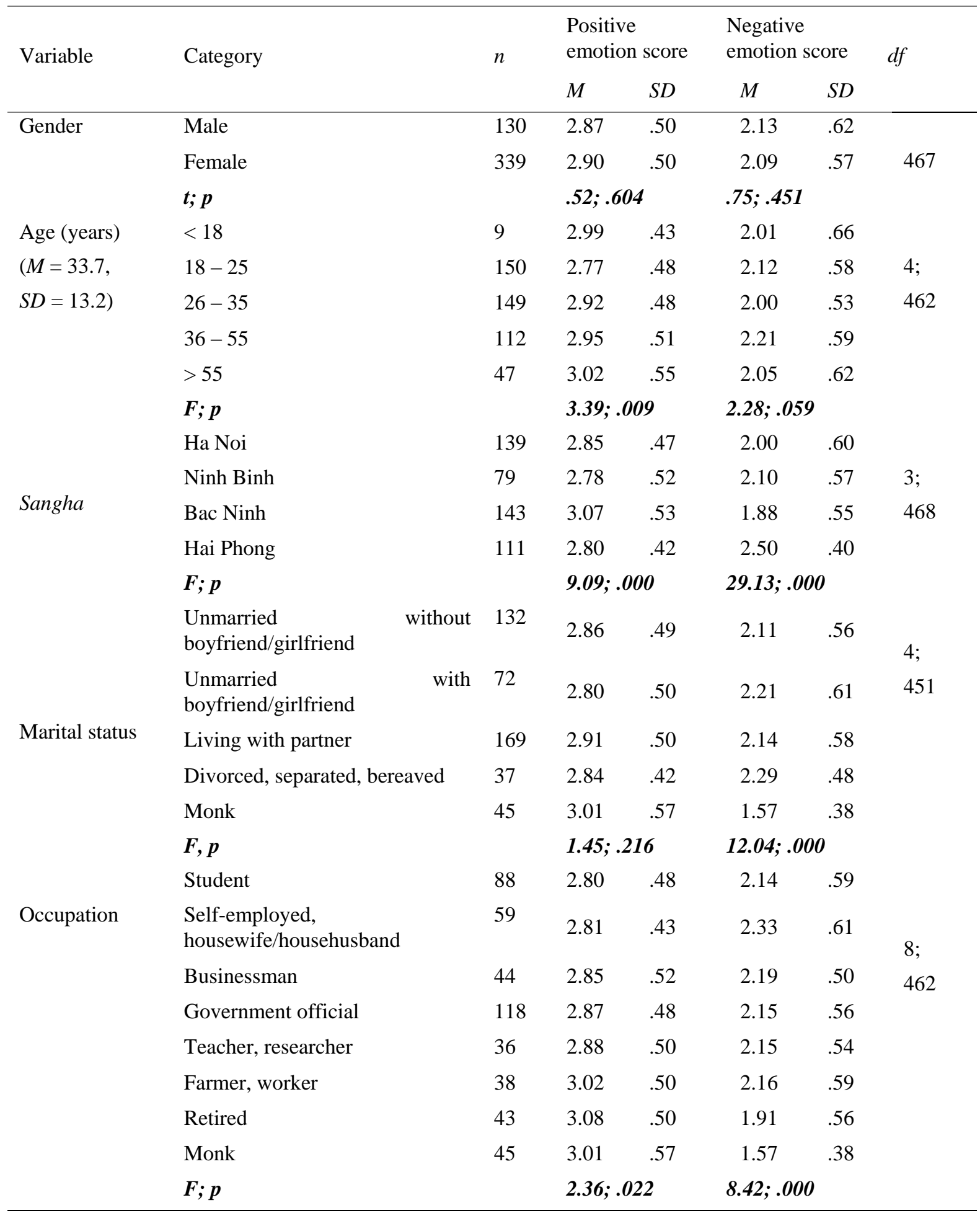

Gender: An independent samples T-test revealed that there was no significant effect of gender on positive emotion scores, $t(467)=.52, p=.604$, and on negative emotion scores, $t(467)=.75, p=.451$. 
Age: One-way ANOVA analysis showed that there was a significant effect of age on positive emotions, $F(4,462)$ $=3.39, p=.009$. Particularly, those who were older than 55 had higher positive scores than those who were between 18 and $25, p<.001$.

Sangha: One-way ANOVA analysis showed that there were significant effects of Buddhist sanghas on positive emotion scores, $F(3,468)=9.09, p<.001$, and on negative emotion scores, $F(3,468)=29.13, p<.001$. To be more specific, participants in Bac Ninh sangha on average had a higher positive emotion score than those in Hanoi sangha $(p=.002)$, Ninh Binh sangha $(p=.001)$, and Hai Phong sangha $(p<.001)$. On the other hands, participants in Hai Phong sangha on average had a higher negative emotion score than participants in other sanghas $(p<.001)$. Furthermore, participants in Ninh Binh sangha had higher negative emotion scores than those in Ninh Binh sangha, $p=.039$. Detail results are presented in the Table 2. Note that Bac Ninh sangha had the largest number of monks and nuns $(n=14)$ and that Buddhist participants at this sangha practiced more frequently than those from the other three.

Table 2. Relationships between emotion scores and sanghas

\begin{tabular}{lll}
\hline Sangha & Positive emotions & Negative emotions \\
\hline (1) Hanoi & $(3)>(1), \mathrm{p}=.002$ & $(1)<(4), \mathrm{p}=.000$ \\
(2) Ninh Binh & $(3)>(2), \mathrm{p}=.001$ & $(2)>(3), \mathrm{p}=.039$ \\
(3) Bac Ninh & $(3)>(4), \mathrm{p}=.000$ & $(3)<(4), \mathrm{p}=.000$ \\
(4) Hai Phong & & $(2)<(4), \mathrm{p}=.000$ \\
\hline
\end{tabular}

Marital status: One-way ANOVA analysis showed that while marital status did not significantly influence positive emotion scores, there was a significant effect of marital status on negative emotion scores, $F(4,451)=$ $12.04, p<.001$. Monks and nuns, who dedicated themselves to non-marital lifestyle, had on average a lower negative emotion score than did other participants (Table 1). There was not any significant difference between other marital status groups.

Occupation: One-way ANOVA analysis showed that although occupation did not have any significant effect on positive emotion scores, it had significant effects on negative emotion scores, $F(8,464)=8.42, p<.001$. Monks and nuns had lower negative emotion scores than participants in other groups $(p<.001)$. Additionally, the retired also had lower negative emotion scores than the self-employed and housewives/househusbands $(p=.005)$.

In summary, age and sangha were the only two demographic variables that significantly influenced positive emotion scores. It was revealed that people who were more than 55 years old had higher positive emotion scores that those who were from 18 to 25 and that participants in Bac Ninh sangha had higher positive emotion scores than participants in other sanghas. Regarding to negative emotion scores, except for monks and nuns there was only a significant difference between the retired and the self-employed and housewives/househusbands. Therefore, demographic variables did not have large effects on participants' emotions in our Buddhist sample.

\subsection{Relationships between Buddhist Variables and Positive and Negative Emotions}

The relationships between religious variables and positive and negative emotions are described in Table 3 .

Buddhist status: An independent samples T-test analysis showed that monks and nuns had significant lower negative emotion scores than did laypeople, $t(470)=9.17, p<.001$. Additionally, there were significant differences between those who had taken refuge in the Three Jewels and those who had not in both positive emotion scores, $F(439)=5.09, p<.001$, and negative emotion scores, $F(439)=9.90, p<.001$. Particularly, those who had taken refuge in the Three Jewels had a higher average positive emotion scores $(M=3.03, S D$ $=.51)$ than those who had not $(M=2.79, S D=.46)$. On the contrary, those who had not taken refuge had higher negative emotion scores $(M=1.81, S D=.51)$ than those who had $(M=2.32, S D=.54)$.

Time of taking refuge in Three Jewels: Time of taking refuge in Three Jewels did not have any significant effect on positive and negative emotion scores of Buddhist participants in our sample $(p>.005)$.

Place of practice: One-way ANOVA analysis showed that place of practice had significantly effects on positive emotion scores, $F(2,441)=10.52, p<.001$, and negative emotion scores, $F(2,441)=28.98, p<.001$. It followed that people who frequently practiced at pagoda had a higher positive emotion average score than did 
those who practiced at home $(p=.002)$ and at other places $(p<.001)$. In contrast, they had a lower negative emotion average score than those who practiced at home $(p<.001)$ and at other places $(p<.001)$.

Table 3. Relationships between Buddhist variables and positive and negative emotions

\begin{tabular}{|c|c|c|c|c|c|c|c|}
\hline \multirow[t]{2}{*}{ Variable } & \multirow[t]{2}{*}{ Group } & \multirow[t]{2}{*}{$N$} & $\begin{array}{l}\text { Positive } \\
\text { scores }\end{array}$ & emotion & $\begin{array}{l}\text { Negative } \\
\text { scores }\end{array}$ & emotion & \multirow[t]{2}{*}{$d f$} \\
\hline & & & $M$ & $S D$ & $M$ & $S D$ & \\
\hline \multirow{6}{*}{$\begin{array}{l}\text { Buddhist } \\
\text { status }\end{array}$} & Monk & 45 & 3.01 & .57 & 1.57 & .38 & \multirow{3}{*}{470} \\
\hline & Layperson & 427 & 2.88 & .49 & 2.15 & .57 & \\
\hline & $t ; p$ & & \multicolumn{2}{|l|}{$1.66 ; .097$} & \multicolumn{2}{|l|}{$9.17 ; .000$} & \\
\hline & Take refuge in & 183 & 3.03 & .51 & 1.81 & .51 & \multirow{3}{*}{439} \\
\hline & Haven't taken refuge & 258 & 2.79 & .46 & 2.32 & .54 & \\
\hline & $t, p$ & & $5.09, .000$ & & $9.90, .000$ & & \\
\hline \multirow{4}{*}{$\begin{array}{l}\text { Time since } \\
\text { taking refuge }\end{array}$} & $<5$ years & 66 & 3.00 & .42 & 1.92 & .50 & \multirow{3}{*}{$2 ; 129$} \\
\hline & $5-10$ years & 46 & 3.07 & .49 & 1.86 & .51 & \\
\hline & $>10$ years & 20 & 3.13 & .78 & 1.60 & .59 & \\
\hline & $t, p$ & & $.53 ; .585$ & & $2.97 ; .055$ & & \\
\hline \multirow{4}{*}{$\begin{array}{l}\text { Place } \\
\text { practice }\end{array}$} & At home & 194 & 2.83 & .46 & 2.23 & .57 & \multirow{3}{*}{$2 ; 441$} \\
\hline & In Pagoda & 196 & 3.01 & .55 & 1.86 & .55 & \\
\hline & Others places & 54 & 2.72 & .41 & 2.36 & .51 & \\
\hline & $F ; p$ & & $10.52 ; .000$ & & $28.98 ; .000$ & & \\
\hline \multirow[t]{5}{*}{ Practice with } & Alone & 104 & 2.91 & .50 & 2.02 & .58 & \multirow{5}{*}{$3 ; 434$} \\
\hline & Friends & 107 & 2.75 & .48 & 2.29 & .58 & \\
\hline & Family members & 89 & 2.82 & .52 & 2.27 & .55 & \\
\hline & Sangha & 138 & 3.05 & .44 & 1.86 & .53 & \\
\hline & $F ; p$ & & $8.83 ; .000$ & & $16.00 ; .000$ & & \\
\hline \multirow{6}{*}{$\begin{array}{l}\text { Frequency of } \\
\text { practice }\end{array}$} & Never & 25 & 2.80 & .56 & 2.09 & .66 & \multirow{6}{*}{$4 ; 462$} \\
\hline & Several times a year & 102 & 2.67 & .41 & 2.40 & .50 & \\
\hline & $1-4$ times a month & 82 & 2.98 & .46 & 2.04 & .51 & \\
\hline & More than once a week & 88 & 2.83 & .49 & 2.22 & .60 & \\
\hline & Everyday & 170 & 3.03 & .51 & 1.89 & .55 & \\
\hline & $F ; p$ & & $9.67 ; .000$ & & $15.14 ; .000$ & & \\
\hline \multirow{6}{*}{$\begin{array}{l}\text { Belief } \\
\text { dharma }\end{array}$} & Strongly believe & 206 & 3.00 & .52 & 1.94 & .60 & \multirow{6}{*}{$4 ; 467$} \\
\hline & Believe & 189 & 2.88 & .47 & 2.17 & .54 & \\
\hline & Quite believe & 49 & 2.59 & .38 & 2.29 & .58 & \\
\hline & Somewhat believe & 14 & 2.61 & .37 & 2.38 & .27 & \\
\hline & Don't believe & 14 & 2.78 & .46 & 2.47 & .62 & \\
\hline & $F ; p$ & & $8.75 ; .000$ & & $8.36 ; .000$ & & \\
\hline \multirow{5}{*}{$\begin{array}{l}\text { Change of } \\
\text { mind since } \\
\text { practicing } \\
\text { dharma }\end{array}$} & Very positive & 217 & 3.06 & .48 & 1.94 & .61 & \multirow{5}{*}{$4 ; 465$} \\
\hline & Positive & 219 & 2.77 & .47 & 2.19 & .51 & \\
\hline & Not at all & 26 & 2.66 & .36 & 2.47 & .52 & \\
\hline & Negative & 7 & 2.63 & .62 & 2.70 & .31 & \\
\hline & $F, p$ & & $8.75 ; .000$ & & $8.36 ; .000$ & & \\
\hline
\end{tabular}

Who people practiced with: One-way ONOVA analysis showed that who people practiced with had significant influence on positive emotion scores $(F(3,434)=8.83, p<.001)$ and on negative emotion scores $(F(3,434)=$ $16.00, p<.001)$. Those who practiced with sangha had higher positive emotion scores than those practicing with a group of friends $(p<.001)$ and with family members $(p=.003)$. In contrast, those practicing with sangha had 
lower negative emotion scores than those practicing with friends $(p<.001)$ and family members $(p<.001)$. Additionally, people practicing alone also had lower negative emotion scores than those practicing with friends $(p=.002)$ or family members $(p=.011)$. Detail results are included in Table 4.

Table 4. Relationships between who people practiced with and emotion scores

\begin{tabular}{lll}
\hline Group & Positive emotions & Negative emotions \\
\hline (1) Alone & & $(1)<(2), \mathrm{p}=.002$ \\
(2) Friends & $(4)>(2), \mathrm{p}=.000$ & $(4)<(2), \mathrm{p}=.000$ \\
(3) Family members & & $(1)<(3), \mathrm{p}=.011$ \\
(4) Sangha & $(4)>(3), \mathrm{p}=.003$ & $(4)<(3), \mathrm{p}=.000$
\end{tabular}

Frequency of practicing dharma: One-way ANOVA analysis showed that frequency of practicing dharma had significant effects on positive emotion scores, $F(4,462)=9.67, p<.001$, and on negative emotion scores, $F(4$, $462)=15.14, p<.001$ (Table 3). Generally, those who practiced dharma daily (at least one per day) had the highest positive emotion scores and the lowest negative emotion scores. The average positive emotion score of this group was significantly higher than that of those who practiced once to four times a month and that of those who only practiced several times a year. Additionally, those who practiced once to four times a month had a higher average positive emotion scores than those who practiced several times a month. In contrast, those who practiced daily had a lower average negative emotion score than that of those who practiced more than one per week and that of those who practiced several times a year. Those who practiced one to four times a month had lower negative score than those who practiced several times a year. Results, therefore, showed that there were emotional differences among four groups, excluding participants who never practiced (Table 5).

Belief in dharma: One-way ANOVA analysis showed that belief in dharma (Buddhist teaching) had significant effects on positive emotion scores, $F(4,467)=8.75, p<.001$, and on negative emotion scores, $F(4,467)=8.36$, $p<.001$ (Table 3 ). More specifically, those who strongly believed in dharma had higher positive emotion scores than those who quite believed $(p<.001)$ and those who somewhat believed $(p=.041)$. Furthermore, those who believed in dharma had higher positive emotion scores than those who quite believed $(p=.002)$. In contrast, negative emotion scores of those who strongly believed were lower than that of those who believed $(p=.001)$, quite believed $(p=.004)$, and somewhat believed $(p<.001)$ (Table 6).

Table 5. Relationships between frequency of practicing dharma and emotions

\begin{tabular}{lll}
\hline Frequency of practice & Positive emotion scores & Negative emotion scores \\
\hline (1) Never & & \\
(2) Several times a year & $(5)>(2), p=.000$ & $(2)>(3), p=.000$ \\
(3) $1-4$ times a month & $(3)>(2), p=.000$ & $(3)<(2), p=.000$ \\
(4) More than once a week & $(4)<(5), p=.023$ & $(5)<(4), p=.000$ \\
(5) Everyday & $(5)>(4), p=.023$ & $(5)<(2), p=.000$ \\
\hline
\end{tabular}

Table 6. Relationships between belief in dharma and emotions

\begin{tabular}{lll}
\hline Belief in dharma & Positive emotion scores & Negative emotion scores \\
\hline (1) Strongly believe & $(1)>(3), \mathrm{p}=.000$ & $(1)<(2), \mathrm{p}=.001$ \\
(2) Believe & $(2)>(3), \mathrm{p}=.002$ & $(1)<(3), \mathrm{p}=.004$ \\
(3) Quite believe & & $(1)<(4), \mathrm{p}=.000$ \\
(4) Somewhat believe & $(1)>(4), \mathrm{p}=.041$ & \\
(5) Don't believe & & \\
\hline
\end{tabular}


Change of mind since practicing dharma: One-way ANOVA analysis showed that change of mind since practicing dharma had significant effects on positive emotion scores, $F(4,458)=16.38, p<.001$, and on negative emotion scores, $F(4,458)=14.40, p<.001$. On one hand, the more positively people assessed their changes, the higher they scored. More specifically, those who held a very positive view about their changes scored higher on the STAI than did those who thought that they had changed positively $(p<.001)$, those who thought that they had not changed at all $(p<.001)$, and those who thought that they had changed negatively $(p$ $<.001)$. On the other hands, those who thought that they had changed very positively scored significantly lower than did those who thought that they had changed positively $(p<.001)$, those who thought that they had not changed at all $(p<.001)$, and those who thought that they had changed negatively $(p<.001)$.

In summary, religious variables influenced greatly positive and negative emotion scores of Buddhists in our sample. Those who took refuge in the Three Jewels, practiced at pagoda, practiced with sangha or alone, practiced frequently, strongly believed in dharma, or assessed their changes positively since practicing dharma had higher positive emotion scores and lower negative emotion scores than the other.

\subsection{Correlations between Nonattachment and Emotions and Factors Predicting Buddhist Emotions}

First, results showed that the entire sample of participants had a nonattachment mean of $4.37, S D=.81$. American adults who did not practice meditation had a nonattachment mean of $4.39(S D=.76)$, whereas that of those who practiced meditation was $4.64(S D=.82)$ (Sahdra et al., 2010).

Second, Pearson bivariate correlation analysis showed that there was a negative correlation between positive and negative emotion subscales, $r=-.38, p<.01$. Additionally, nonattachmment was positively correlated to positive emotions $(r=.47, p<.01)$ and negatively correlated to negative emotions $(r=-.37, p<.01)$.

Third, multivariate linear regression analysis showed that frequency of practice and belief in dharma could predict $16 \%$ of the nonattachment variance, $R^{2} \Delta=.16, F=47.40, p<.001$. Frequency of practice was a better predictor $(\beta$ $=.32, t=6.81, p<.001)$ than belief in dharma $(\beta=.14, t=2.93, p=.004)$ (Table 7).

Table 7. Multivariate linear regression models frequency of practice and belief in dharma on nonattachment

\begin{tabular}{|c|c|c|c|c|c|c|c|c|}
\hline \multirow[t]{2}{*}{ Variables } & \multirow[t]{2}{*}{$R^{2}$} & \multirow[t]{2}{*}{$R^{2} \Delta$} & \multirow[t]{2}{*}{$F$} & \multicolumn{2}{|c|}{$\begin{array}{l}\text { Unstandardised } \\
\text { Coefficients }\end{array}$} & \multirow{2}{*}{$\begin{array}{l}\text { Standardised } \\
\text { coefficients } \\
\beta\end{array}$} & \multirow[t]{2}{*}{$t$} & \multirow[t]{2}{*}{$p$} \\
\hline & & & & $B$ & $S E$ & & & \\
\hline & .17 & .16 & 47.40 & 3.85 & .15 & & & .000 \\
\hline $\begin{array}{l}\text { Frequency } \\
\text { practicing dharma }\end{array}$ & of & & & .19 & .03 & .32 & 6.81 & .000 \\
\hline Belief in dharma & & & & .11 & .04 & .14 & 2.93 & .004 \\
\hline
\end{tabular}

It was also revealed that frequency of practice and belief in dharma could predict $5.8 \%$ percent of the positive emotion variance $\left(R^{2} \Delta=.058, F(2,464)=15.22, p<.001\right)$ and $8.1 \%$ percent of negative emotion variance $\left(R^{2} \Delta\right.$ $=.081, F(2,464)=21.52, p<.001)$. More specifically, frequency of practice was a better predictor of positive emotions $(\beta=.15, t=2.93, p=.003)$ than belief in dharma $(\beta=.14, t=2.76, p=.006)$.

Finally, univariate linear regression showed that nonattachment could predict $21.7 \%$ positive emotion $\left(R^{2}=.217\right.$, $F(1,469)=131.61, p<.001)$ and $12.4 \%$ negative emotion $\left(R^{2}=.124, F(1,469)=73.23, p<.001\right)$. Nonattachment improved positive emotions and reduced negative emotions (Table 8 ).

Table 8. Univariate linear regression models of nonattachment on emotions

\begin{tabular}{|c|c|c|c|c|c|c|c|c|}
\hline \multirow[t]{2}{*}{ Variables } & \multirow[t]{2}{*}{$R^{2}$} & \multirow[t]{2}{*}{$R^{2} \Delta$} & \multirow[t]{2}{*}{$F$} & \multicolumn{2}{|c|}{$\begin{array}{l}\text { Unstandardised } \\
\text { Coefficients }\end{array}$} & \multirow{2}{*}{$\begin{array}{l}\text { Standardised } \\
\text { coefficients } \\
\beta\end{array}$} & \multirow[t]{2}{*}{$t$} & \multirow[t]{2}{*}{$p$} \\
\hline & & & & $B$ & $S E$ & & & \\
\hline Positive emotion & .217 & .215 & 131.61 & .08 & .01 & .46 & 11.47 & .000 \\
\hline Negative emotion & .124 & .122 & 73.23 & -.09 & -.01 & -.36 & -8.55 & .000 \\
\hline
\end{tabular}




\section{Discussion}

First, among demographic variables only age had significant effects on positive emotions of participants. More specifically, those who were more than 55 years old had higher positive emotions than those who were 18 to 25 years old did. It could be the case that participants in the former group had retired and did not have to suffer as much stress as those who were still studying and working and that the elder may have had more experience coping with stress. Additionally, because age can influence brain activity, brain activity of those who were 18 to 25 may produce more excitatory neurotransmitters than inhibitory neurotransmitters and thus young adults were more generally excited by stresses, compared to those who were older. In regards to Buddhist practice, the elder could have practiced Buddhism for longer time and thus were less likely to be affected by negative emotions.

Second, all religious variables had significant effects on positive and negative emotions. More specifically, people with strong religious commitment such as monks, lay-people who practiced at pagoda, and lay-people who practiced with sangha had higher positive emotion and less negative emotion scores than those whose religious commitment were weak. The result that those who strongly believed in dharma also had higher positive emotions and lower negative emotions than did those who quite believed and those who somewhat believed suggests future research to replicate our findings, as well as to explore underlying mechanisms.

Third, our findings showed that frequency of practice was positively correlated to positive emotions of participants. Furthermore, frequency of practice could predict positive and negative emotions better than belief in dharma did, which is consistent with Buddhist teachings that discourage unconditional faith in the teachings and that encourage personal practice and learning, as evidenced in the Kalama sutra.

Do not go upon what has been acquired by repeated hearing; nor upon tradition; nor upon rumor; nor upon what is in a scripture; nor upon surmise; nor upon an axiom; nor upon specious reasoning; nor upon a bias towards a notion that has been pondered over; nor upon another's seeming ability; nor upon the consideration, 'The monk is our teacher.' Kalamas, when you yourselves know: 'These things are bad; these things are blamable; these things are censured by the wise; undertaken and observed, these things lead to harm and ill,' abandon them (Thera, 2013).

Buddhism, therefore, promotes free thinking, deep experiences, and individual examination of theory and practice in order to discover the most suitable teachings and methods for oneself. Blinded beliefs in anything, including Buddhist teachings, should be criticized and avoided. This result agrees with what was observed in a study by Winzer and Gray (2018) that "it was not being Buddhists alone that [made] people happier and healthier, but how frequently they engage in Buddhist practices and how regularly they apply Buddhist values in their behaviors that leads to better health" (p. 12).

Additionally, practicing indepedently is a unique and essential element of practicing Buddhism. In addition to practicing mindfulness in everyday tasks and speeches, diligent Buddhist practitioners dedicate their time to work with their own minds through meditation. Our results showed that those who frequently practiced indepedently had lower negative emotions than those who practiced with their friends or family members, suggesting that private practices had beneficial effects on practitioners' emotions. A similar result suggesting that private Buddhist practices could actually yield more fruitful benefits than group practices was documented in a study by Johnstone and his colleagues (2012). They found that although Buddhists engaged less frequently in organized religious practices than in private religious practices, private practice was the only variable that was positively correlated with general mental health. The result of the present study suggests an alternative approach to regulating negative emotions, compared to the modern psychology theory that focuses on coping with individuals' relationships with other people. Therefore, Sahdra and her colleagues (2013) believed that Buddhist teachings and the modern psychology theory could complement each other in order to create an outstanding personal development model that is based on individuals' working with their own minds to reduce defensiveness, improve mental clarity, self-compassion, and empathy, and promote prosocial behaviors. This suggests that working with the mind should be considered as the foundation for personal emotional regulation and thus enhancing interpersonal relationships. Such an approach can be summarized in one sentence: personal transformation is the best foundation for achieving happiness and satisfactory relationships.

In sum, our results provide supporting evidence for the role of nonattachment, considered as both a Buddhist practice method and result of such a practice, in emotional regulation. Furthermore, Winzer and Gray (2018) concluded that by regulating negative emotions, improving family and community connections, and strengthening positive emotions, religion had an indirect impact on health. Taken together, the two studies suggest that future research should examine the link between nonattachment and physical and mental health in both religious and nonreligious groups. 
Limitations of our study include the lack of emotional frequency analysis and the measurement of positive and negative emotions. First, although our study provided evidence for the relations between nonattachment and positive and negative emotions in a Buddhist sample, there was not enough data to further analyze the uniqueness of positive emotions in Buddhists. Some scholars have found several differences between Buddhist emotional expression and that of other religious adherents. Accordingly, a Buddhist might seek out emotions that are low arousal in their pleasantness (Silberman, 2005; Tsai et al., 2007). A study by Kim-Prieto \& Diener (2009) on five different religions, including Christianity, Islam, Hinduism, Judaism, and Buddhism, also found that while participants in other groups were notable for their heightened experience of particular emotions, the Buddhist participants did not show high frequency of any of the emotions assessed. Thus, our study fails to examine to what extent did nonattachment influence the emotional frequency of participants. Our second limitation involved the use of STAI, which is a reliable tool for anxiety but not for negative and positive emotions. Thus, the accuracy of our measure of positive and negative emotions may be limited. Taken into accout our limitations, future research should replicate our findings using validated scale that assessing positive and negative emotions. It is also pertient to investigate a potential moderate frequency of Buddhist emotional expression, as expected in the discussed theory background.

\section{Conclusion and Implication}

Nonattachment was positively correlated to positive emotions and negatively correlated to negative emotions. Furthermore, it could predict the increase of positive emotions and the decrease of negative emotions of our Buddhist participants. Among demographic and religious variables, religious commitment had positive influences on participants. Specifically, practicing dharma had more significant positive effects on participants' emotions than belief in dharma did. These results suggest applying nonattachment practice to promote positive emotions and reduce negative emotions and incorporating it in psychological treatment for those who have emotional problems.

\section{References}

Coffey, K. A., \& Hartman, M. (2008). Mechanisms of action in the inverse relationship between mindfulness and psychological distress. Complementary Health Practice Review, 13, 79-91. https://doi.org/10.1177/1533210108316307

Desbordes, G., Gard, T., Hoge, E. A., Hölzel, B. K., Kerr, C., \& Lazar, S. W., et al. (2015). Moving beyond mindfulness: defining equanimity as an outcome measure in meditation and contemplative research. Mindfulness, 6, 356-372. https://doi.org/10.1007/s12671-013-0269-8

Emmons, R. A. (2005). Emotion and religion. In R.F. Paloutzian, \& C.L. Park (Eds.), Handbook of the psychology of religion and spirituality (pp. 235-252). New York: Guilford Press.

Emmons, R. A., \& Paloutzian, R. F. (2003). The psychology of religion. Annual Review of Psychology, 54, 377-402. https://doi.org/10.1146/annurev.psych.54.101601.145024

Fiori, K. L., Brown, E. E., Cortina, K. S., \& Antonucci, T. C. (2006). Locus of control as a mediator of the relationship between religiosity and life satisfaction: Age, race, and gender differences. Mental Health, Religion \& Culture, 9, 239-263. https://doi.org/10.1080/13694670600615482

Gleg, A. (2016). External Mindfulness, Secure (Non)-Attachment, and Healing Relational Trauma: Emerging Models of Wellness for Modern Buddhists and Buddhist Modernism. Journal of Global Buddhism, 17, $1-21$.

Harris, E. J. (1997). Detachment and Compassion in Early Buddhism. Bodhi Leaves Publication No. 141. Buddhist Publication Society Kandy, Sri Lanka.

Kim-Prieto, C., \& Diener, E. (2009). Religion as a source of variation in the experience of positive and negative emotions. The Journal of Positive Psychology, 4, 447-460. https://doi.org/10.1080/17439760903271025

Koenig, H. G., \& Larson, D. B. (2001). Religion and mental health: Evidence for an association. International Review of Psychiatry, 13, 67-78. https://doi.org/10.1080/09540260124661

Johnstone, B., Yoon, D. P., Cohen, D., Schopp, L. H., McCormack, G., Campbell, J., \& Smith, M. (2012). Relationships among spirituality, religious practices, personality factors, and health for five different faith traditions. Journal of Religion and Health, 51, 1017-1041. https://doi.org/10.1007/s10943-012-9615-8

McCullough, M. E., \& Willoughby, B. L. (2009). Religion, self-regulation, and self-control: Associations, explana- tions, and implications. Psychological Bulletin, 135, 69-93. https://doi.org/10.1037/a0014213 
Myers, D. G. (1992). The pursuit of happiness: Discovering the pathway to fulfillment, well-being, and enduring personal joy. New York: William Morrow and Company.

Pargament, K. I., Magyar-Russell, G. M., \& Murray-Swank, N. A. (2005). The sacred and the search for significance: Religion as a unique process. Journal of Social Issues, 61, 665-687. https://doi.org/10.1111/j.1540-4560.2005.00426.x

Park, C. (2005). Religion as a meaning-making framework in coping with life stress. Journal of Social Issues, 61, 707-729. https://doi.org/10.1111/j.1540-4560.2005.00428.x

Philippot, P., Chapelle, G., \& Blairy, S. (2002). Respiratory feedback in the generation of emotion. Cognition \& Emotion, 16, 605-607. https://doi.org/10.1080/02699930143000392

Sahdra, B. K., Shaver, P. R., \& Brown, K. W. (2010). A scale to measure nonattachment: A Buddhist complement to Western research on attachment and adaptive functioning. Journal of Personality Assessment, 92, 116-127. https://doi.org/10.1080/00223890903425960

Sahdra, B. K., \& Shaver, P. R. (2013). Comparing Attachment Theory and Buddhist Psychology. The International Journal for the Psychology of Religion, 23, 282-293. https://doi.org/10.1080/10508619.2013.795821

Sahdra B. K., Ciarrochi J., Parker P. D., Marshall S., \& Heaven P. (2015). Empathy and nonattachment independently predict peer nominations of prosocial behavior of adolescents. Frontiers in Psychology, 6, 263. https://doi.org/10.3389/fpsyg.2015.00263

Silberman, I. (2005). Religion as a meaning system: Implications for the New Millennium. Journal of Social Issues, 61(4), 641-663. https://doi.org/10.1111/j.1540-4560.2005.00425.x

Silva, P. (2013, November 30). The psychology of emotions in Buddhist perspective. Retrieved from http://www.accesstoinsight.org/lib/authors/desilva-p/wheel237.html

Spielberger, C. D., Gorsuch, R. L., Lushene, R., Vagg, P. R., \& Jacobs, G. A. (1983). Manual for the State-Trait Anxiety Inventory. Palo Alto, CA: Consulting Psychologists Press.

Szekely, R. D., Opre, A., \& Miu, A. C. (2015). Religiosity enhances emotion and deontological choice in moral dilemmas. Personality and Individual Differences, 79, 104-109. https://doi.org/10.1016/j.paid.2015.01.036

Thera S. (2013, November 30). Kalama sutra: The Buddha's charter of free inquiry. Retrieved from http://www.accesstoinsight.org/lib/authors/soma/wheel008.html

Tsai, J. L., Miao, F. F., \& Seppala, E. (2007). Good feelings in Christianity and Buddhism: Religious differences in ideal affect. Personality and Social Psychology Bulletin, 33, 409-421. https://doi.org/10.1177/0146167206296107

Wang, S., Wong Y. J., \& Yeh K. (2016). Relationship harmony, dialectical coping, and nonattachment: Chinese indigenous well-being and mental health. The Counseling Psychologist, 44, 78-108. https://doi.org/10.1177/0011000015616463

Winzer, L., \& Gray, R. S. (2018). The Role of Buddhist Practices in Happiness and Health in Thailand: A Structural Equation Model. Journal of Happiness Studies, 1. https://doi.org/10.1007/s10902-017-9953-Z

\section{Copyrights}

Copyright for this article is retained by the author(s), with first publication rights granted to the journal.

This is an open-access article distributed under the terms and conditions of the Creative Commons Attribution license (http://creativecommons.org/licenses/by/4.0/). 